\title{
ADEQUAÇÕES CURRICULARES DO CURSO DE DESIGN DE MODA DA UNIVERSIDADE PARANANENSE - UNIPAR
}

Curricular adaptations of fashion design course at the University Parananense-Unipar

\section{PINI, Ana Paula Pereira I Especialista}

Universidade Paranaense - UNIPAR

anapaulap@unipar.br

\section{CARNEIRO, Luciane do Prado I Mestre}

Universidade Paranaense - UNIPAR

luciane@unipar.br

\section{Resumo}

A indústria de Moda e Vestuário vem se expandindo no Paraná e instituições que oferecem cursos voltados à área também. $\mathrm{O}$ Curso de Tecnologia em Design de Moda da UNIPAR em Cascavel partiu da iniciativa da comunidade empresarial e política da região, em decorrência dos resultados obtidos em pesquisas, que diagnosticaram a grande quantidade de indústrias de micro e médio porte existentes na área de confecção, como também o elevado número de empregos que esta atividade gera para a comunidade, necessitando assim de profissionalização através de um curso superior.

Palavras Chave: Design de Moda; Indústria de Confecção; Unipar.

\section{Abstract}

The Garment and fashion industry has been expanding in Paraná and institutions that offer courses to the area too. Course of technology in fashion Design at UNIPAR on Rattlesnake left the initiative of the business community and politics of the region, due to the results obtained in surveys, which diagnosed the large amount of micro and medium-sized industries in the area of production, but also the large number of jobs that this activity generates for the community, necessitating that professionalization through college.

Keywords: Fashion Design; Knitting industry; Unipar. 


\section{INTRODUC̣ÃO}

A formação do profissional da área da Moda está cada dia mais centralizada nos cursos superiores desta área, deste modo cabe salientar a importância dos mesmos e da discussão em torno dos planos pedagógicos e curriculares destes cursos. De modo geral a discussão sobre o projeto pedagógico dos cursos superiores em Moda, reafirma o compromisso das instituições em primar sempre pelo melhor conteúdo, transportando pelos projetos de pesquisa, ensino e extensão valor agregado ao aprendizado acadêmico.

É neste âmbito que se enseja as propostas das instituições de ensino voltadas ao estudo e compreensão da área do design de moda, abrangendo deste modo todas as disciplinas que promovem o aprendizado destas cátedras e aperfeiçoando o domínio destes conhecimentos a nível superior.

Neste contexto, a UNIPAR fornece a seus acadêmicos informação e conhecimento que vão além da intuição, visa transportar o acadêmico através do conhecimento teórico para a vivencia prática do conceito de aprendizagem e cognição.

A indústria da moda que é crescente no Brasil, e torna-se a cada dia mais profissionalizada, exige dos seus cursos de graduação e pós graduação, o cumprimento de lançar ao mercado de trabalho pessoas capacitadas e com concreta formação.

\section{Breve análise sobre a institucionalização do Ensino de Moda no Brasil}

Em uma análise comparativa entre o ensino de Moda no Brasil e em outros países, pode-se perceber que no Brasil esta atividade iniciou-se tardiamente. Foi somente em 1987 que o Bacharelado em Desenho de Moda da Faculdade Santa Marcelina, com ênfase em criação nas áreas de vestuário, calçados e acessórios, joalheria e fotografia iniciou-se. Este curso foi originado a partir do curso de Artes Plásticas e apresenta grande parte do seu corpo docente formado nas áreas de Artes e Moda. (BISNETO; PEREIRA, 2013)

Posteriormente, em 1989, foram autorizados pelo MEC os cursos de Bacharelado em Negócios da Moda, na Universidade Anhembi Morumbi, e o Bacharelado em Moda, na Universidade Paulista, ambos na cidade de São Paulo, com as primeiras turmas iniciadas em 1990. Assim, os três primeiros cursos de moda do Brasil foram cursos de bacharelado que se alinhavam às áreas de Artes, Moda e Negócios. (BISNETO; PEREIRA, 2013) 
A fim de atender a indústrias de outras regiões do país, muitos cursos de nível superior foram criados: Universidade de Caxias do Sul, UCS, no Rio Grande do Sul (1993); Universidade Federal do Ceará, UFC, em Fortaleza (1994); Universidade Veiga de Almeida, UVA, na cidade do Rio de Janeiro (1995); Universidade Estadual de Santa Catarina, UDESC, em Florianópolis (1996); Universidade Estadual de Londrina, UEL, no Paraná (1997); Universidade Tuiuti do Paraná, UTP, em Curitiba (1997); Universidade Regional de Blumenau, em Santa Catarina (1997); Centro de Educação Superior de Maringá, Cesumar, no Paraná (1999). (PIRES, 2002)

Já no início dos anos 2000 houve um expressivo aumento da oferta de novos cursos superiores de Moda em todo país, a maioria deles com nomeação de Design de Moda, Bisneto e Pereira (2013) descrevem "amplia-se também a abertura dos novos cursos nas modalidades de Sequencial de Formação Específica e Cursos Superiores de Tecnologia (CST), [...] enquanto decresce comparativamente o número de novos cursos na modalidade de bacharelado."

\section{Histórico do curso de tecnologia em Design de Moda - Unidade Cascavel}

O Curso de Tecnologia em Design de Moda foi implantado na Unidade/ Campus - Cascavel - PR, da UNIPAR, no ano de 2003 através do Parecer № 436/01 de 02/04/2001 e Resolução UNIPAR № 13/01 de 20/06/2001, com funcionamento no turno noturno.

Em março de 2001 iniciou-se um trabalho pioneiro no município de Cascavel, onde pela iniciativa da Prefeitura Municipal, através da Secretaria da Indústria, Comércio e Turismo e da CODEVEL (Companhia de Desenvolvimento de (ascavel), buscou-se parcerias com várias entidades que pudessem desenvolver um trabalho junto ao setor do vestuário. Estava nascendo o projeto "Polo do Vestuário do Oeste do Paraná", tendo a UNIPAR como uma de suas parceiras.

De acordo com O Projeto Pedagógico do Curso (UNIVERSIDADE PARANAENSE, 2013) o grupo gestor formado para elaborar, diagnosticar e traçar ações que pudessem fortalecer este setor entendeu que, dentre tantas ações, seria necessário a implantação de um curso de nível superior em Tecnologia que pudesse formar profissionais na área de moda. Levando-se em conta que a moda têm feito parte da cultura e da economia da sociedade contemporânea, 
nada mais oportuno que a criação do curso superior de Tecnologia em Gestão de Moda e Estilo na cidade de Cascavel.

A microrregião de Cascavel abriga uma população de cerca de 428.510 habitantes e está dividida em dezoito municípios. A cidade de Cascavel se situa a $520 \mathrm{~km}$ da capital e conta com uma população de 286.205 habitantes (Censo 2010), com estimativa de 305.615 para 2013, sendo sua grande maioria residente na área urbana. O ciclo da madeira, entre os anos 30 e 40, atraiu grande número de famílias de Santa Catarina, Rio Grande do Sul e em especial colonos poloneses, alemães e italianos que, juntos, formaram a base populacional da cidade. (UNIVERSIDADE PARANAENSE, 2013)

Atualmente, Cascavel recebe o título de Capital do Oeste Paranaense, sendo um dos maiores centros econômicos do Paraná. O município é considerado também o pólo universitário do oeste devido ao número de instituições de ensino superior (duas universidades e diversas faculdades), das quais é pertinente mencionar a Universidade Estadual do Oeste do Paraná e a Universidade Paranaense.

A partir da análise da realidade e com o propósito de contribuir para a melhoria da qualidade de vida da comunidade em que está inserida, a Universidade Paranaense - UNIPAR criou o curso Superior de Tecnologia em Gestão de Moda e Estilo. Quando a primeira turma iniciou-se em 2003, houve certa dificuldade em encontrar professores habilitados, devido à localização geográfica, problema que aos poucos foi sanado.

Já em 2006 inicia-se a primeira turma de pós-graduação em Gestão de Moda, o que evidenciou ainda mais a instituição e o curso. Sempre com turmas com um ótimo número de alunos, o curso trouxe diferencial para a região oeste do Paraná, pois esta tem um crescente número de empresas ligadas ao ramo da confecção e necessitava de profissionais que viessem acrescentar diferencial para a moda da região. Em seu $11 \%$ ano de existência, o curso apresenta todos os anos uma boa procura por parte de interessados em profissionalizar-se e também por parte dos empresários, que procuram a Unipar buscando auxílio, tanto de acadêmicos quanto de recém-formados, para estágios e contratações. O Curso também é ofertado nas Unidades de Cianorte e Umuarama. (UNIVERSIDADE PARANAENSE, 2013).

A primeira matriz instituída para o curso teve três anos de duração, de 2003 a 2005, o curso denominava-se Curso Superior de Tecnologia em Gestão de Moda e Estilo. Tendo como eixo norteador a Gestão da Produção. Quando os cursos de Moda foram inseridos no eixo do Design em 2006 através do Decreto número 5.773/2006 - Catálogo Nacional de Cursos Superiores de 
Tecnologia MEC - com a implantação do novo Catálogo de Cursos Superiores de Tecnologia passou a denominar-se Curso Superior de Tecnologia em Design de Moda, buscando assim uma unificação na identidade nominativa dos mesmos.

Quadro 01 - MatrizCurricular de 2003 a 2005

Unidade: CAMPUS - CASCAVEL, CIANORTE

CurSO: TECNOLOGIA EM GESTÃO DE MODA E ESTILO

Graduação: TECNÓLOGO Regime: SERIADO/ANUAL

Duração: 3 (TRÊS) ANOS LETIVOS

Integralização: tempo total - mínimo $=3$ (três) anos letivos máximo $=5$ (cinco)

anos letivos - tempo útil (carga horária) $=1.792 \mathrm{~h} /$ aula

\begin{tabular}{|l|l|}
\hline 1a Série - Disciplinas & C/H \\
\hline Portugues instrumental & 64 \\
\hline Metodologia do trabalho cientifico & 64 \\
\hline Ingles tecnico & 64 \\
\hline Gestão industrial & 64 \\
\hline Desenho de moda i & 64 \\
\hline Desenho planificado & 64 \\
\hline Historia da arte & 64 \\
\hline Modelagem plana i & 64 \\
\hline Tecnologia da confecção & 64 \\
\hline Tecnologia textil I & 64 \\
\hline 2a Série - Disciplinas & $\mathbf{C / H}$ \\
\hline Gestão industrial II & 64 \\
\hline Desenho de moda II & 64 \\
\hline Modelagem plana II & 64 \\
\hline Marketing em moda & 64 \\
\hline Historia da indumentaria & 64 \\
\hline Informatica aplicada I & 64 \\
\hline Aspectos sociologicos da vestimenta & 64 \\
\hline Tecnologia textil II & 64 \\
\hline
\end{tabular}




\begin{tabular}{|l|c|}
\hline Laboratorio de criação & 64 \\
\hline Planejamento de coleçao I & 64 \\
\hline 3a Série - Disciplinas & C/H \\
\hline Gestão industrial III & 64 \\
\hline Desenho de ilustração & 64 \\
\hline Laboratorio de criação II & 64 \\
\hline Modelagem tridimensional & 64 \\
\hline Informatica aplicada I & 64 \\
\hline Desenvolvimento de produto & 64 \\
\hline Estagio supervisionado em moda e estilo & 128 \\
\hline Total geral de Horas/aula & $\mathbf{1 . 7 9 2}$ \\
\hline
\end{tabular}

Fonte: Autor (baseado em informações dos PPC's dos anos descritos)

Para atender a esta nova nomenclatura e adequar-se às novas diretrizes, entre os anos de 2007 a 2013 uma segunda Matriz Curricular foi concebida, desta vez tendo como eixo norteador o Planejamento de Produto, com algumas adequações durante o período, porém sem mudanças nas disciplinas ofertadas. (Quadro 2)

Quadro 02 - Matriz Curricular de 2006 a 2013

\begin{tabular}{|l|c|}
\hline 3a Série - Disciplinas & C/H \\
\hline Empreendedorismo & 80 \\
\hline Modelagem plana II & 80 \\
\hline História da moda & 80 \\
\hline Execução de produto & 160 \\
\hline Modelagem computadorizada & 80 \\
\hline Gestão de moda & 80 \\
\hline Desenho técnico e computadorizado II & 80 \\
\hline Estágio supervisionado em design de moda & 80 \\
\hline Total geral de Horas/aula & $\mathbf{2 . 0 8 0}$ \\
\hline
\end{tabular}




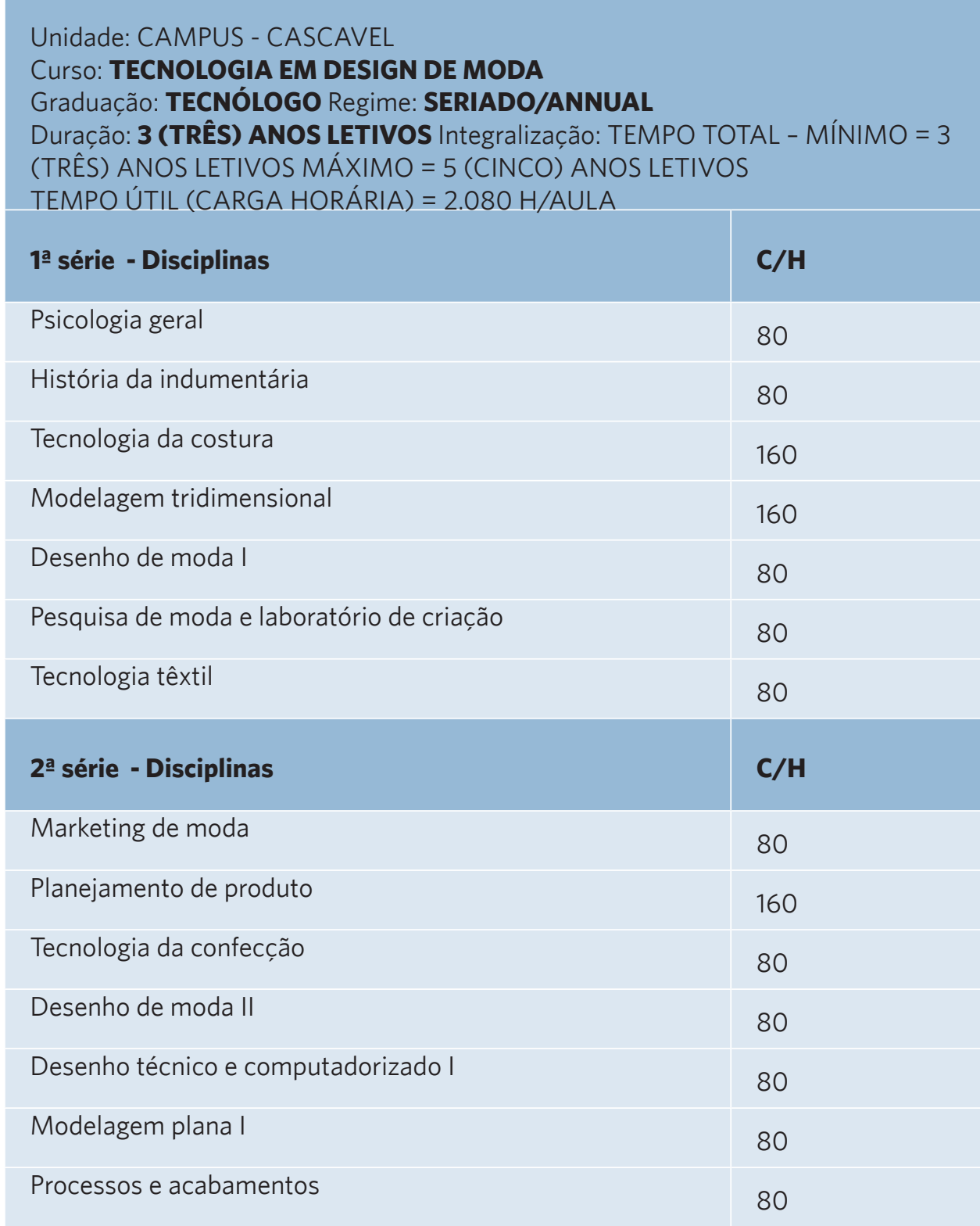

Fonte: Autor (baseado em informações dos PPC's dos anos descritos).

Em 2010 as matrizes curriculares foram adequadas em atendimento à Resolução CONSEPE n.o 01/2010, de 26/03/2010 que referendou o Ato Executivo da Reitoria, de 28/12/2009.

O tecnólogo em Design de Moda elabora e gerencia projetos para a indústria de confecção do vestuário, considerando fatores estéticos, simbólicos, ergonômicos e produtivos. A pesquisa de tendências de comportamento, cores, formas, texturas e acabamentos; o estilismo em moda; o desenvolvimento de produtos de moda aplicando visão histórica, sociológica e prospectiva; a elaboração 
de portfólios e dossiês; a representação gráfica de suas criações; a elaboração de protótipos e modelos, além da análise de viabilidade técnica do projeto, são algumas das atividades deste profissional. (BRASIL, 2010).

O Curso atende também o disposto pelo Decreto № 5.626, de 22 de dezembro de 2005 que regulamenta a Lei no 10.436, de 24 de abril de 2002, que dispõe sobre a Língua Brasileira de Sinais - Libras, como disciplina optativa a todos os cursos superiores de graduação, e o art. 18 da Lei no 10.098, de 19 de dezembro de 2000. Assim o presente PPC do Curso de Tecnologia em Design de Moda inseriu a disciplina de Língua Brasileira de Sinais - LIBRAS como disciplina optativa. (UNIVERSIDADE PARANAENSE, 2013).

No Projeto Pedagógico do Curso Superior de Tecnologia em Design de Moda além dos conteúdos estabelecidos nas Legislações descritas acima, os alunos compartilham uma formação transversal de conteúdos referentes às Políticas de Educação Ambiental (Lei n.o 9.795, de 27 de abril de 1999 e Decreto no 4.281/2002), Relações Étnico-raciais (Resolução CNE/CP n.ㅇ 01, de 17 de junho de 2004) e Educação em Direitos Humanos - EDH (Resolução CNE/CP n.o 01, de 30 de maio de 2012), de forma disciplinar obrigatória, e de enriquecimento curricular ou de projetos de ensino, pesquisa e extensão universitária. (UNIVERSIDADE PARANAENSE, 2013).

Baseando-se nestas diretrizes e analisando o novo perfil do profissional ingressante e também dos egressos, o Núcleo Docente Estruturante (NDE) das Unidades onde o curso é ofertado, em reuniões, através de pesquisas e análises, optou por propor uma nova matriz a partir de 2014, adequando algumas nomenclaturas de disciplinas, reestruturando conteúdos e remodelando a matriz alterando a série em que algumas cadeiras são ofertadas.

Modernizando assim a estrutura curricular do curso, cujo objetivo é formar tecnólogos com capacidade de desenvolvimento intelectual autônomo e permanente, éticos e comprometidos, com conhecimentos técnicos, humanísticos, ambientais e histórico-sociais necessários ao entendimento, interpretação e intervenção na realidade nacional e regional. Instrumentalizandoos com métodos, técnicas e recursos que possibilitem uma atuação condigna e competente nas suas funções na área de Design. (Quadro 3). 
Quadro 03 - Matriz Curricular a partir de 2014

Unidade:CASCAVEL, CIANORTE, UMUARAMA

Curso:DESIGN DE MODA (Eixo Tecnológico: Produção Cultural e Design)

Graduação: TECNOLÓGICA Regime: SERIADO ANUAL - NOTURNO

Duração: 3 (TRÊS) ANOS LETIVOS Integralização: A) TEMPO TOTAL - MÍNIMO

$=03$ (TRÊS) ANOS LETIVOS - MÁXIMO = 05 (CINCO) ANOS LETIVOS B)

TEMPO ÚTIL (Carga Horária) $=\mathbf{2 . 0 8 0}$ H/AULA $\left(^{\star}\right)$

\begin{tabular}{|l|c|}
\hline 1a série - Disciplinas & C/H \\
\hline Psicologia geral & 80 \\
\hline História da arte e indumentária & 80 \\
\hline Tecnologia da costura & 80 \\
\hline Introdução a modelagem & 80 \\
\hline Introdução ao desenho de moda & 80 \\
\hline Pesquisa e criação de moda & 80 \\
\hline Materiais têxtis & 80 \\
\hline Metodologia de design & 80 \\
\hline 2a série - Disciplinas & $\mathbf{C} / \mathbf{H}$ \\
\hline
\end{tabular}

História da moda

Planejamento de produto

Tecnologia da confecção

Desenho de moda avançado

Desenho técnico e computadorizado

Modelagem intermediária

Processos e acabamentos têxteis

80

$3^{a}$ série - Disciplinas $\quad \mathbf{C} / \mathbf{H}$

Marketing de moda

Execução de produto 160

Modelagem computadorizada

Design gráfico de moda

Gestão e empreendedorismo de moda 


\begin{tabular}{|l|l|}
\hline Modelagem avançada & 80 \\
\hline Temas em design de moda & 80 \\
\hline Estágio supervisionado & 80 \\
\hline Total geral de Horas/aula & $\mathbf{2 . 0 8 0}$ \\
\hline
\end{tabular}

Fonte: Autor (baseado em informações dos PPC's dos anos descritos)

Com essas mudanças referidas, busca-se formar um profissional que possa cumprir com os objetivos específicos do curso, conforme descrito em seu PPC:

- Promover o desenvolvimento de competências e habilidades que permitam atuar na área da indústria do vestuário e afins;

- Identificar, analisar e aplicar ferramentas metodológicas do projeto tendo em mente responsabilidade profissional ética respeitando os valores da cidadania e responsabilidade social;

- Pesquisar nos vários meios existentes, buscando referências para o desenvolvimento de projetos na área de criação de novos produtos;

- Através da metodologia projetual, estruturar e pôr em prática as diferentes etapas pelas quais o produto de moda passa, desde a interpretação das tendências até o final do produto;

- Reconhecer as várias matérias primas, produtos químicos, e os processos de transformação.

- Conhecer e operar os maquinários básicos que compõem a indústria de confecção;

- Conhecer os processos que modificam as características originais dos substratos têxteis;

- Conhecer as normas e leis obrigatórias de reconhecimento das matérias primas e conservação dos produtos com relação às etiquetas;

- Conhecer e elaborar os processos de modelagem, tendo em mente a ergonomia aplicada à moda; 
- Conhecer normas de padronização de medidas para modelagens para os diversos segmentos, público consumidor e como aplicá-la na prática;

- Conhecer e operar softwares específicos de estilo e modelagem;

- Pesquisar as tendências de moda internacionais e nacionais e apresentar novas propostas;

- Propor criação de coleção para diversos segmentos do mercado e de público alvo;

- Adequar os substratos têxteis ao estilo, modelagem, segmento do mercado e público alvo;

- Desenvolver produtos visando seu ciclo de vida e sua durabilidade;

- Organizar e gerenciar o fluxo do projeto de desenvolvimento do produto;

- Conhecer e acompanhar a programação e planejamento de compras das matérias primas, aviamentos e produtos manufaturados;

- Analisar as necessidades humanas e os sistemas produtivos, buscando relacioná-los entre si através de uma abordagem integrada do vestuário.

De acordo ainda com o PPC do curso e a partir das competências e das habilidades gerais do egresso do Curso de Graduação em Tecnologia em Design de Moda da UNIPAR, consoante o que dispõe o art.6. e 7.ำ da Resolução CNE/CP n. 03, de 18 de dezembro de 2002 deve ser assegurado, no perfil do formando egresso a capacidade de articular e colocar em ação conhecimentos, habilidades, atitudes e valores necessários para o desempenho eficiente e eficaz de atitudes requeridas pela natureza do trabalho e pelo desenvolvimento tecnológico.

O Egresso do Curso Superior de Tecnologia em Design de Moda da UNIPAR deve caracterizar-se pela busca do conhecimento das tecnologias focadas em Design de Moda, tendo como área Artes, Comunicação e Design e buscando como objeto de sua formação e desenvolvimento de suas habilidades e competências, que resultam na atuação Técnica, Ética e Social. Para isso deve demonstrar interesse em buscar novas soluções para os problemas vividos dentro das indústrias de confecção relacionada à tecnologia e ao meio ambiente.

Considera-se autêntico, o egresso de Tecnologia em Design de Moda desta universidade, aquele que assume uma postura ética responsável, que 
respeite as diferenças e exerça seus direitos relativos a áreas em que atua. $\mathrm{O}$ perfil desejado do egresso em Design de Moda se orienta no Conselho Nacional de Educação.

Contemplar a capacitação criativa para unificar os domínios técnicos e processo criativo, desenvolvendo com conhecimento tecnológico e soluções inovadoras conhecedor do processo que insere o setor de desenvolvimento do produto na cadeia têxtil, do gerenciamento de produção, inserindo conhecimento na qualidade, produtividade, arranjo físico da fábrica, estoques, custos e investimentos além de interagir na área de recursos humanos para propiciar qualidade de vida e preservação do meio ambiente. Capaz de transformar as informações sobre o comportamento do produto em influências versus tendências.

Atuarem no desenvolvimento de produtos com a finalidade de caracterizar-se pelo conhecimento técnico de diversos segmentos de atividade, conhecimento artístico e histórico, conhecimento de metodologias e capacidade de reflexão critica que permitam a produção projetual da área.

Assim, o Curso Superior de Tecnologia em Design de Moda da Universidade Paranaense - UNIPAR, deve possibilitar, no perfil específico do egresso, as seguintes competências e habilidades:

- Gerenciar projetos para a indústria de confecção do vestuário;

- Considerar fatores estéticos, ergonômicos e produtivos;

- Pesquisar tendências de comportamento, cores, formas, texturas e acabamentos;

- Desenvolver produtos de moda aplicando visão histórica sociológica e prospectiva;

- Elaborar portfólios e dossiês;

- Representar graficamente suas criações;

- Elaborar protótipos e modelos;

- Analisar a viabilidade técnica do projeto. 


\section{REFERÊNCIAS}

BISNETO, J. P. M.; PEREIRA, S. E. Gestão ou design de vestuário? O ensino da moda na Bahia. Revista Gestão e Planejamento, Salvador, v. 14, n. 1, p. 157-176, jan./abr. 2013. Disponível em: <http://www.revistas. unifacs.br/index.php/rgb>. Acesso em: 3 maio 2014.

BRASIL. Ministério da Educação. Catálogo Nacional de Cursos Superiores de Tecnologia. 2006. Disponível em: <http://www.unicentro.br/dirai/ legislacao/Legislacao-base-Ensino-Superior/Tecnologo/catalogo_ completo.pdf>. Acesso em: 9 abr. 2014.

BRASIL. Ministério da Educação. Catálogo Nacional de Cursos Superiores de Tecnologia. 2010. Disponível em: <http://portal.mec.gov.br/index. php? Itemid=86\&id=12352\&option= com_content $\&>$. Acesso em: 20 abr. 2014.

PIRES, D. B. A história dos cursos de design de moda no Brasil. Revista Nexos: estudos em comunicação e educação especial moda, São Paulo, v. 6, n. 9, p. 1-13, 2002. Disponível em: <http://www.inovacaoedesign. com.br/artigos_cientificos/db_historia_escola_design_moda_1_.pdf $>$. Acesso em: 8 jun. 2014.

SILVA, B. C.; NASCIMENTO, L. C. P. Apontamentos acerca da integração entre conteúdos de design e de moda no percurso de implementação do design de moda. 2012. Disponível em: <http://www.uel.br/revistas/uel/ index.php/projetica/article/viewFile/12266/11334>. Acesso em: 17 maio 2014.

UNIVERSIDADE PARANAENSE. Curso Superior de Tecnologia em Design de Moda. Disponível em: <http://presencial.unipar.br/cursos/ graduacao/curso-superior-de-tecnologia-em-design-de-moda/>. Acesso em: 7 abr. 2014.

UNIVERSIDADE PARANAENSE. Projeto Pedagógico do Curso de Tecnologia em Design de Moda. Cascavel: Unipar, 2014. 


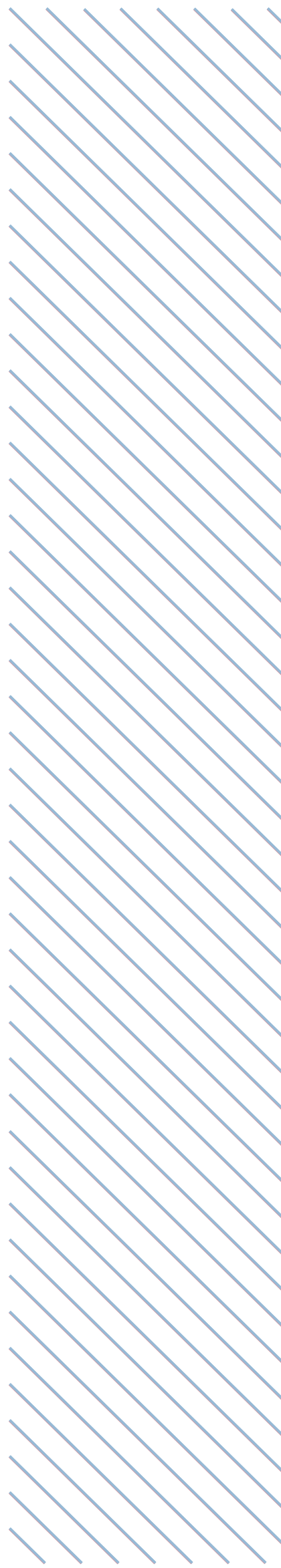

